\title{
Soluble CD146 is generated by ectodomain shedding of membrane CD146 in a calcium-induced, matrix metalloprotease-dependent process
}

\author{
Eva-Maria Boneberg a,*, Harald Illges ${ }^{\mathrm{a}, \mathrm{b}}$, Daniel F. Legler ${ }^{\mathrm{a}}$, Gregor Fürstenberger ${ }^{\mathrm{c}}$ \\ a Biotechnology Institute Thurgau, Unterseestrasse 47, Kreuzlingen 8280, Switzerland \\ b Department of Natural Sciences, Immunology and Cell Biology, University of Applied Sciences, Rheinbach 53359, Germany \\ ' Tumor and Breast Center ZeTuP, St. Gallen 9006, Switzerland
}

Keywords:

CD146

Shedding

Endothelial cells

Matrix metalloproteases

Vascular permeability

\begin{abstract}
A B S T R A C T
CD146 is a cell adhesion molecule localized at the endothelial junction and is involved in the control of cell cell cohesion. In this study, we showed that calcium influx in human microvascular lung endothelial cells results in the loss of surface CD146 and the release of soluble CD146. This calcium induced CD146 shedding could be prevented with inhibitors of matrix metalloproteases indicating a central role of matrix metalloproteases in this process. We also investigated if CD146 shedding influences vascular permeability. Endothelial cell monolayers cultured on filter membranes showed an increased permeability for albumin when stimulated with ionomycin. This calcium induced increase in permeability was inhibited when CD146 shedding was prevented by a matrix metalloprotease inhibitor. Our data indicate that surface CD146 plays a central role in the regulation of vascular permeability and demonstrate that CD146 and matrix metalloproteases are potential targets to modify endothelial barrier function.
\end{abstract}

\section{Introduction}

Endothelial cells line the vessel wall and control vascular permeability, homeostasis and leukocyte migration from the blood into the surrounding tissue. To sustain this function, the endothelial monolayer requires effective intercellular junctions that regulate cell cell contacts. These cell contacts are made up of adherens and tight junctions that are both composed of various adhesion molecules and interacting cytoskeletal proteins. The typical transmembrane protein in adherens junctions is vascular endothelial (VE ) cadherin, while occludin and members of the claudin family are present in tight junctions (Dejana, 2004). In addition, other adhesive molecules are localized outside these structures, for example, platelet endothelial cell adhesion molecule 1 (PECAM 1, CD31) and CD146 (Dejana, 2004; Bardin et al., 2001). CD146 (also referred to as MUC18, MCAM, Mel CAM, S Endo 1, P1H12 antigen) was initially identified as a marker of tumor progression and metastasis formation in human melanoma (Lehmann et al., 1989; Shih et al., 1997a; Bardin et al., 1996). CD146 is homologous to several cell adhesion molecules and belongs to the immunoglobulin superfamily containing five extracellular immuno globulin like domains, a single transmembrane domain and a short cytoplasmic domain (Sers et al., 1993). Beside its expression in malignant melanocytes, CD146 is constitutively expressed in all endothelial cells, irrespective of the anatomical localization (Bardin

\footnotetext{
* Corresponding author. Fax: + 41716785021.

E-mail address: eva.maria.boneberg@bitg.ch (E.-M. Boneberg).
}

et al., 1996). CD146 localizes at the endothelial junction, but outside the adherens junction and colocalizes with the actin cytoskeleton (Bardin et al., 2001). It is involved in the control of cell cohesion: CD146 expression is upregulated when endothelial cells reach confluence and transfection of fibroblasts with CD146 reduces paracellular permeability (Bardin et al., 2001; Solovey et al., 2001; Shih et al., 1997b). Moreover, knockdown of CD146 expression with CD146 siRNA resulted in impaired proliferation, adhesion and migration of human umbilical vein endothelial cells (HUVEC) indicating a key role of CD146 in endothelial cell activity and angiogenesis (Kang et al., 2006).

The physiological ligand of CD146 is not yet identified. However, crosslinking of CD146 by a specific monoclonal antibody initiates an outside in signaling cascade in human umbilical vein endothelial cells that results in calcium influx involving the protein tyrosine kinases FYN, FAK and paxillin (Anfosso et al., 2001). This observation suggests that calcium influx could be the physiological response of endothelial cells to the engagement of CD146 by its ligand.

In addition to the membrane anchored form of CD146, a soluble form was found in the supernatant of cultured human endothelial cells and in human plasma (Bardin et al., 1998). Compared to matched healthy controls, plasma levels of sCD146 were increased in patients with chronic renal failure indicating that increased plasma levels of sCD146 reflect impaired endothelial monolayer integrity (Bardin et al., 2003). Further sCD146 plasma levels were increased in patients with recurrent pregnancy loss (Pasquier et al., 2005), polymyositis (Figarella Branger et al., 2006) and diabetic nephropathy (Saito et al., 2007). 
Soluble forms of surface receptors can be generated by alternative splicing of the respective mRNA or by proteolytic cleavage of surface molecules, a process referred to as ectodomain shedding. The mechanism responsible for the generation of soluble CD146 is not yet identified.

The aim of this study was to elucidate the role of soluble CD146: we investigated in human primary endothelial cells the mechanism of sCD146 generation and the stimuli that could induce formation of soluble CD146. Furthermore, we analyzed the impact of sCD146 generation on vascular permeability.

\section{Materials and methods}

\section{Materials}

Ionomycin, PMA, LPS (Salmonella abortus equi), Brefeldin A and Pepstatin were purchased from Sigma, Buchs, Switzerland. A23187, MMP Inhibitor I (FN 439), MMP Inhibitor III and MMP 3 Inhibitor I (Stromelysin Inhibitor, Ac RCGVPD $\mathrm{NH}_{2}$ ) were purchased from Cal biochem (Lucerne, Switzerland). Forskolin was purchased from Biotrend (Cologne, Germany) and human recombinant TNF $\alpha$ from Tebu (Offenbach, Germany). Aprotinin and E64 were purchased from Biomol, Hamburg, Germany.

\section{Cell culture}

Human microvascular lung endothelial cells (HMVEC L) and human umbilical vein endothelial cells (HUVEC) were purchased from Clonetics (Lonza, Verviers, Belgium). HMVEC L were cultured with endothelial basal medium (EBM 2, Clonetics) supplemented with EGM 2 SingleQuots (Clonetics) containing fetal bovine serum, human VEGF, human FGF B, human EGF, human R3 IGF 1, ascorbic acid, heparin, hydrocortisone and gentamycin/amphotericin B. Cells were subcultured when they reached 70 90\% confluence and were split $1: 2$, usually twice a week. Cells were only used until passage 15 as recommended by Clonetics and no differences were observed between early and late passages in the reaction of the cells to the stimuli used in these experiments. HUVEC were grown in M199 medium (Sigma) supplemented with $20 \%$ fetal bovine serum, $80 \mathrm{U} / \mathrm{ml}$ heparin (Liquemin ${ }^{\circledR}$, Roche, Reinach, Switzerland), $40 \mu \mathrm{g} / \mathrm{ml}$ bovine brain extract (Lonza), $2 \mathrm{mM}$ Ultraglutamine (Lonza) and $100 \mathrm{IU} / \mathrm{ml}$ penicillin/streptomycin (Lonza) on cell culture plates coated with $2 \%$ gelatin solution (Sigma).

For stimulation experiments, cells were seeded in 24 well plates (Greiner, Frickenhausen, Germany) in their respective medium. On the next day, fresh medium was added and the cells (70 90\% confluent) were stimulated with the calcium ionophores ionomycin (Sigma, Switzerland) or A23187 (Calbiochem, Switzerland) at various concentrations. After incubating the cells at $37{ }^{\circ} \mathrm{C}$ for the indicated time, cell culture supernatants were harvested and stored at $80^{\circ} \mathrm{C}$ until ELISA measurement. When MMP inhibitors were used, these inhibitors were added at the same time as the calcium ionophores.

\section{CD146 ELISA}

Soluble CD146 was measured in cell culture supernatants by sandwich ELISA. ELISA plates (TPP, Trasadingen, Switzerland) were coated overnight at $4{ }^{\circ} \mathrm{C}$ with $100 \mu \mathrm{l} /$ well CD146 antibody (clone OJ79c; Serotec, Oxford, UK) with a concentration of $1 \mu \mathrm{g} / \mathrm{ml}$ in PBS After blocking with $200 \mu \mathrm{l} /$ well PBS/3\% BSA for $2 \mathrm{~h}$ at room temperature, the plates were washed twice with $\mathrm{PBS} / 0.05 \%$ Tween 20. Then $100 \mu \mathrm{l}$ cell culture supernatants or recombinant human CD146 as standard (Biocytex, Marseille, France) was added to each well and incubated for $2 \mathrm{~h}$ at room temperature. After 4 wash cycles, biotinylated CD146 antibody (clone P1H12; Chemicon, Hofheim, Germany) was added with a concentration of $0.5 \mu \mathrm{g} / \mathrm{ml}$ in $\mathrm{PBS} / 3 \%$
BSA ( $100 \mu \mathrm{l} /$ well) and incubated for $2 \mathrm{~h}$ at room temperature. After 6 wash cycles, plates were incubated for $30 \mathrm{~min}$ at room temperature with streptavidin peroxidase (Biosource, Nivelles, Belgium; $0.5 \mu \mathrm{g} / \mathrm{ml}$ in $\mathrm{PBS} / 3 \% \mathrm{BSA}, 100 \mu \mathrm{l} /$ well). After 8 washes, $100 \mu \mathrm{l} /$ well TMB liquid substrate solution (Sigma) was added and incubated at room temperature for $5 \mathrm{~min}$. After the addition of $50 \mu \mathrm{l} /$ well $1 \mathrm{M} \mathrm{H}_{2} \mathrm{SO}_{4}$ absorption was measured at $450 \mathrm{~nm}$ using a reference wavelength of $690 \mathrm{~nm}$.

\section{Flow cytometry}

For measurement of surface CD146, HMVEC L were seeded in $25 \mathrm{~cm}^{2}$ flasks (Integra Biosciences). On the next day, fresh medium was added and the cells (70 90\% confluent) were incubated with ionomycin or A23187 at $37{ }^{\circ} \mathrm{C}$ for $1 \mathrm{~h}$. Cells were detached from the cell culture flask with $0.025 \%$ Trypsin/0.01\% EDTA for $1 \mathrm{~min}$. After washing in PBS/10\% FCS, cells were resuspended in $200 \mu \mathrm{l}$ PBS and stained with $1 \mu \mathrm{l}$ of the CD146 specific antibody P1H12 PE (clone $\mathrm{P} 1 \mathrm{H} 12$, Chemicon) for $30 \mathrm{~min}$ at room temperature. Then cells were washed twice with $1 \mathrm{ml}$ PBS and measured in a FACS LSR flow cytometer (BD Biosciences) using Cell Quest software (BD Biosciences).

\section{Permeability assay}

HMVEC L were seeded on BD Biocoat cell culture inserts (24 well format with companion plate, $1 \mu \mathrm{m}$ pore size, transparent mem brane; BD Biosciences) coated with Collagen I. Cells were cultured for 5 days so that cells could form a complete monolayer and fresh supplemented EBM 2 medium was added daily. The permeability assay to assess the barrier function of the endothelial monolayer was performed with Evan's Blue bound to bovine serum albumin. Therefore, $490 \mu \mathrm{l}$ supplemented EBM 2 was added to the inserts and $750 \mu \mathrm{l}$ supplemented EBM 2 was added to the bottom well. Stimuli or inhibitor was added at the indicated concentration to the top and the bottom well. The transport was initiated by adding $10 \mu \mathrm{l}$ of $0.2 \%$ Evan's Blue in FCS to the top well. Cells were incubated for $24 \mathrm{~h}$ at $37^{\circ} \mathrm{C}$. After the incubation time, $200 \mu \mathrm{l}$ of the medium in the bottom well was removed and the absorbance was measured at $620 \mathrm{~nm}$.

\section{CD146 knockdown with siRNA}

HUVEC were transfected with CD146 siRNAs (M CAM Stealth siRNA, Invitrogen) or a control siRNA or mock transfected. Transfec tion was performed with siPORT amine (Ambion, Rotkreuz, Switzer land) in a double knockdown protocol. For this, cells were transfected with $100 \mathrm{nM}$ siRNA in $2 \mathrm{ml}$ antibiotic free DMEM supplemented with $10 \%$ fetal calf serum using $5 \mu$ siPORT Amine. Cells were washed twice with PBS and fresh antibiotic free HUVEC medium was added $24 \mathrm{~h}$ after transfection. This transfection process was repeated 2 days after the first transfection and cells were allowed to recover for $30 \mathrm{~h}$. Then cells were detached with trypsin/EDTA and analyzed for CD146 expression by flow cytometry and used in permeability assays as described above.

\section{Statistical analysis}

All data are given as means + SEM. Statistical analysis was performed with one way ANOVA and Tukey Kramer Multiple Com parisons Test as post test using GraphPad Instat (Instat Statistics, GraphPad Software). 


\section{Results}

\section{Stimulation of CD146 shedding}

In the supernatants of cultured HMVEC L, low amounts of SCD146 could be detected by ELISA measurement. To investigate which stimuli could further increase the formation of sCD146, HMVEC L were incubated with various substances and SCD146 was measured in the cell culture supernatants by ELISA. Since calcium influx could be the physiological response of endothelial cells to the engagement of CD146 by its ligand, the calcium ionophores ionomycin and A23187 were tested for their potential to stimulate the formation of sCD146. Both calcium ionophores induced the formation of SCD146 in a concentration dependent manner (Fig. 1A, B). Maximal induc tion was reached at $10 \mu \mathrm{M}$ for ionomycin and $30 \mu \mathrm{M}$ for $\mathrm{A} 23187$, and higher concentrations of ionophores resulted in reduced amounts of sCD146, probably due to the cellular toxicity of the substances at this high concentration.

The formation of SCD146 could not be induced by stimulation with Forskolin (10 $500 \mu \mathrm{M}$ ), a substance that increases intracellular cAMP levels (data not shown). Also inflammatory stimuli (LPS, $10 \mu \mathrm{g} / \mathrm{ml}$ or TNF $\alpha, 10 \mathrm{ng} / \mathrm{ml}$ ) did not induce the formation of sCD146 (data not shown). PMA $(0.110 \mathrm{ng} / \mathrm{ml}$ ), an activator of protein kinase $\mathrm{C}$, induced only low amounts of sCD146. Combination of PMA with ionomycin did not further increase the ionomycin induced sCD146 levels (data not shown).

Next we determined the kinetics of sCD146 formation. Time course studies with ionomycin or A23187 stimulated HMVEC L showed a
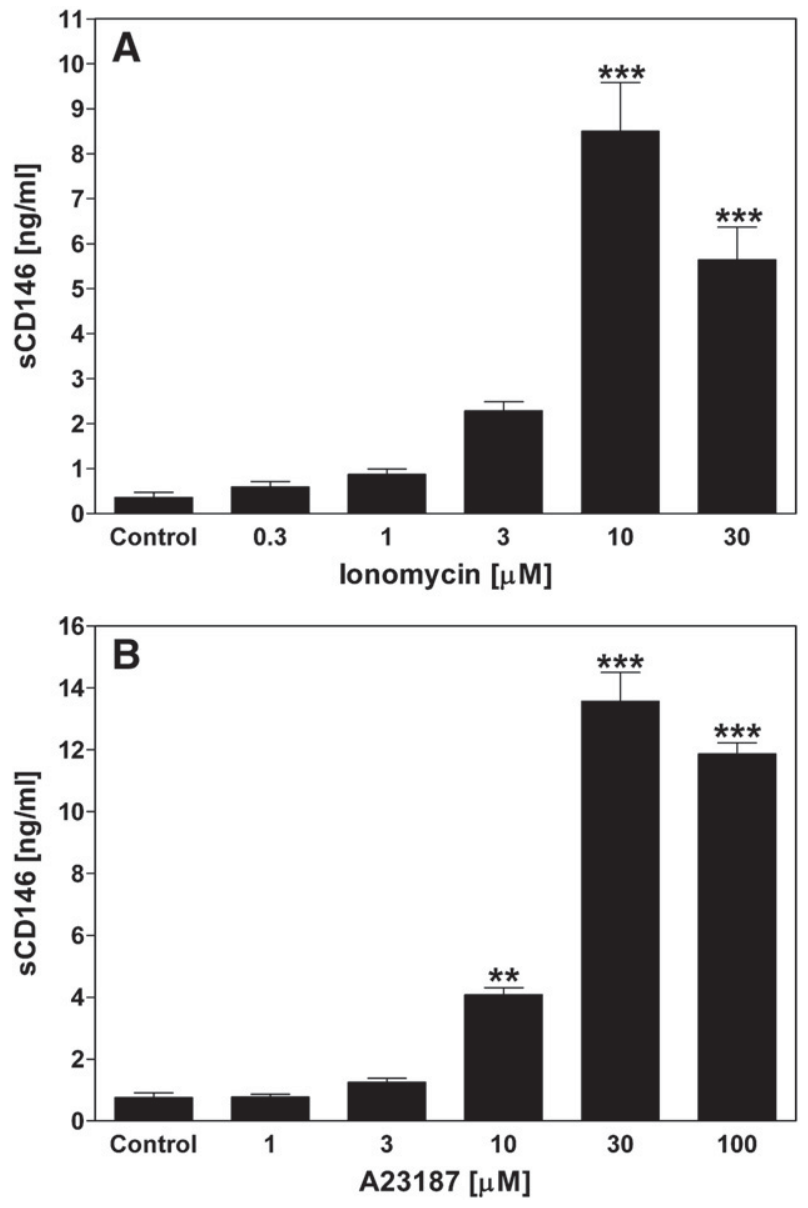

Fig. 1. Calcium ionophores stimulate the generation of soluble CD146. Cultured HMVEC-L were stimulated with different concentrations of ionomycin (A) or A23187 (B) and incubated for $2 \mathrm{~h}$. Soluble CD146 was measured in the cell culture supernatants by ELISA. $*^{*} p<0.01$ and $* * * p<0.001$ versus control. rapid generation of sCD146 (Fig. 2). Already 5 min after stimulation of the cells, increased levels of sCD146 were detectable in the super natants. A strong increase of SCD146 was only observed in the first 20 min, afterward the generation of sCD146 was attenuated. Stimulation of the cells for longer than $1 \mathrm{~h}$ did not result in higher sCD146 levels (data not shown).

The soluble form of CD146 could be generated by alternative splicing of its mRNA or by proteolytic cleavage of surface CD146, a process referred to as ectodomain shedding. The fast kinetics of sCD146 formation indicates either the release of preformed sCD146 or the proteolytic cleavage of surface CD146. To address this question, we stimulated HMVEC L with A23187 or ionomycin for $1 \mathrm{~h}$ and measured the surface expression of CD146 by flow cytometry. The staining of CD146 with fluorescence labeled antibody showed a very high expression on unstimulated cells (median fluorescence intensity: 1104; Fig. 3). Stimulation of HMVEC L with $10 \mu \mathrm{M}$ A23187 separated the cells in two populations: one population displayed a strong decrease in surface CD146 (median fluorescence intensity: 109), whereas the surface expression of the other population was not altered compared to the unstimulated control cells (median fluores cence intensity: 1155). This different response could result from the variable permeability of the cells for A23187, which could be influenced, e.g., by the cell cycle.

The stimulation of HMVEC L with $5 \mu \mathrm{M}$ ionomycin uniformly decreased the amount of surface CD146 on the whole population (median fluorescence intensity: 110). This result suggests that soluble CD146 results from proteolytic cleavage of surface CD146 and not from secretion of a preformed soluble CD146 splice variant. To further confirm this finding, we also incubated HMVEC L with Brefeldin A, a substance that inhibits specifically Golgi mediated secretion of proteins. After $1 \mathrm{~h}$ of preincubation with $5 \mu \mathrm{g} / \mathrm{ml}$ Brefeldin A, cells were stimulated with ionomycin for $2 \mathrm{~h}$. The presence of Brefeldin A did not reduce the amount of SCD146 in the cell culture supernatants $(2.7 \pm 0.07 \mathrm{ng} / \mathrm{ml} \mathrm{sCD} 146$ (mean \pm SEM) for samples stimulated with $5 \mu \mathrm{M}$ ionomycin; $2.4 \pm 0.14 \mathrm{ng} / \mathrm{ml} \mathrm{sCD} 146$ for samples stimulated with ionomycin and $5 \mu \mathrm{g} / \mathrm{ml}$ Brefeldin A). This indicated that soluble sCD146 is generated by shedding of the extracellular domain of CD146 and is not released from the cells via a secretory pathway.

\section{Inhibition of CD146 shedding}

To characterize the proteolytic activity responsible for CD146 shedding, we analyzed a series of protease inhibitors. The broad

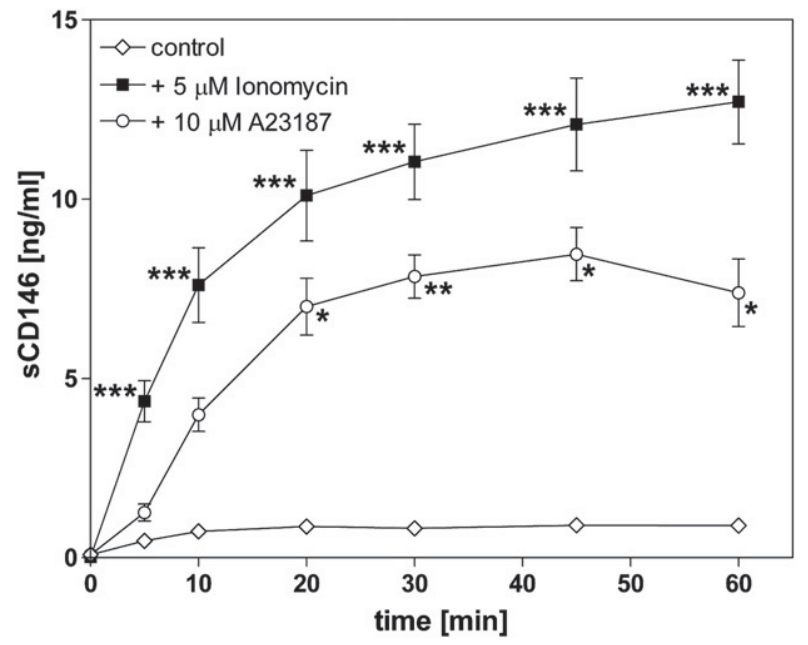

Fig. 2. Time course of sCD146 generation. Cultured HMVEC-L were stimulated with $5 \mu \mathrm{M}$ ionomycin or $10 \mu \mathrm{M}$ A23187 and incubated for the indicated time. Soluble CD146 was measured in the cell culture supernatants by ELISA. ${ }^{*} p<0.05,{ }^{* *} p<0.01$ and ${ }^{* * *} p<0.001$ versus control at the respective time point. 

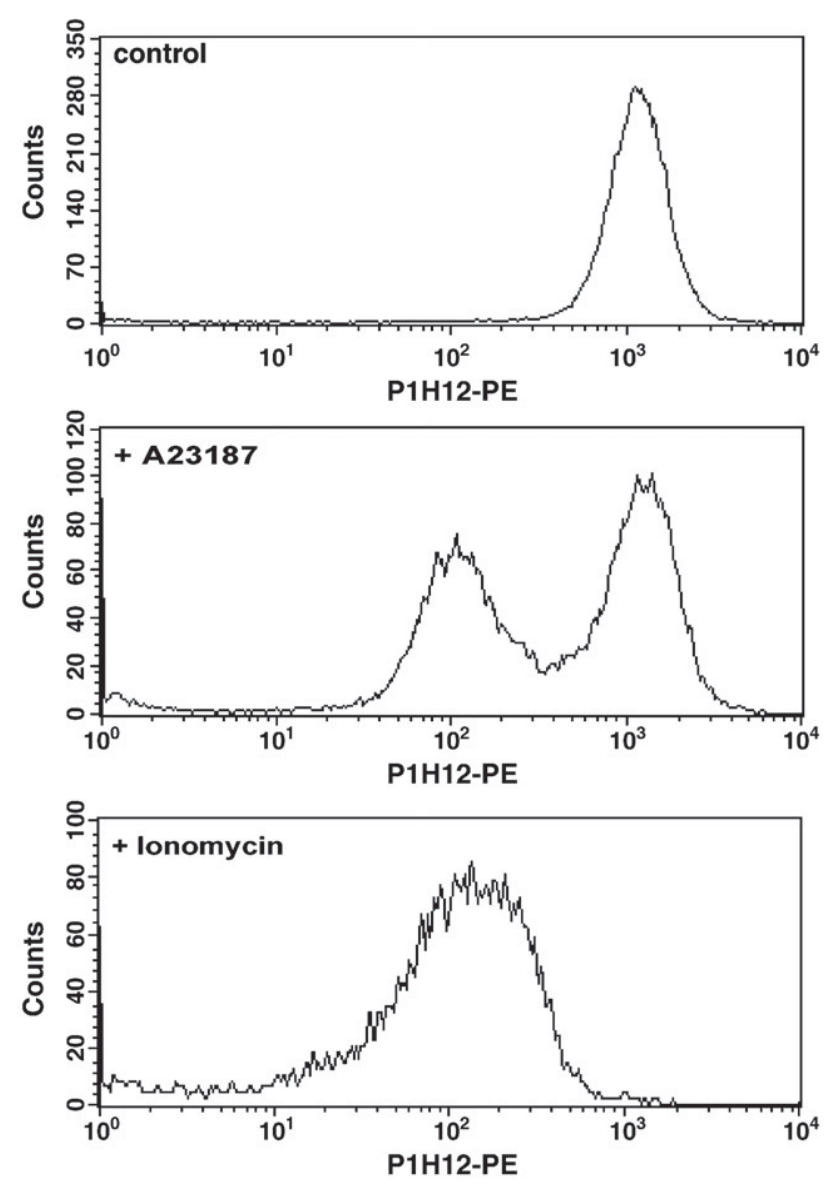

Fig. 3. Calcium ionophores reduce the surface expression of CD146. Cultured HMVEC-L were stimulated with $5 \mu \mathrm{M}$ ionomycin or $10 \mu \mathrm{M}$ A23187 and incubated for $1 \mathrm{~h}$. Expression of CD146 on the cell surface was analyzed by flow cytometry after staining with the CD146 antibody P1H12.

spectrum MMP inhibitors, MMP Inhibitor I and MMP Inhibitor III, both reduced ionomycin induced shedding of CD146 in a concentration dependent manner (Fig. 4A, B). The $\mathrm{IC}_{50}$ was calculated to be $105 \mu \mathrm{M}$ for MMP Inhibitor I and $134 \mathrm{nM}$ for MMP Inhibitor III. Other protease inhibitors as Aprotinin, E64 and Pepstatin did not reduce the release of sCD146 (data not shown). This result indicates that MMPs are involved in the shedding of CD146. MMP Inhibitor I and MMP Inhibitor III both inhibit several MMPs. The analysis of their inhibitory profile showed that only two of the MMPs, MMP 1 and MMP 3, are inhibited by both of them. We therefore tested the influence of an MMP 3 inhibitor on ionomycin induced CD146 shedding. This inhibitor reduced shedding of CD146 in a concentration dependent manner (Fig. 4C). At a concentration of $100 \mu \mathrm{M}$, MMP 3 Inhibitor I blocked $93 \%$ of the ionomycin inducible sCD146 release. The $\mathrm{IC}_{50}$ for this inhibitor was calculated to be $1.7 \mu \mathrm{M}$.

Also in HUVEC, the calcium induced shedding of CD146 could be observed and MMP Inhibitor I and MMP 3 Inhibitor I were able to block CD146 shedding (Fig. 4D).

\section{Influence of CD146 shedding on vascular permeability}

Elevated intracellular calcium concentrations in endothelial cells are known to cause increased vascular permeability (Sandoval et al., 2001; Tiruppathi et al., 2002; Vandenbroucke et al., 2008). We could show that calcium influx also induced shedding of CD146. Thus, we tested if the inhibition of CD146 shedding also inhibits the calcium induced increase in vascular permeability. For this, endothelial cell monolayers were grown in collagen coated filter cell culture inserts.
Vascular permeability was determined by the addition of albumin stained with Evan's Blue to the top well and detection of the penetrated albumin by measuring the optical density in the bottom well after $24 \mathrm{~h}$. Cells stimulated with ionomycin showed a significantly increased permeability for albumin when compared to the unstimu lated control cells (Fig. 5). This calcium induced increase in perme ability was abolished in the presence of $500 \mu \mathrm{M}$ MMP Inhibitor I. This result showed that the blocking of CD146 shedding with an MMP inhibitor also prevented the calcium induced increase in vascular permeability. MMP Inhibitor III and MMP 3 Inhibitor I could not be tested in this assay since they are only soluble in DMSO, and in this $24 \mathrm{~h}$ experiment, DMSO disturbed the integrity of the cell monolayer.

To link the loss of membrane CD146 with the increased vascular permeability, we knocked down the expression of CD146 in HUVEC with siRNA. Transfection of HUVEC with three different CD146 siRNA resulted in a strong downregulation of membrane CD146 as analyzed by flow cytometry (Fig. 6). Concomitantly, with the loss of membrane CD146, we found an increase of vascular permeability. This result indicates that CD146 is important for vascular barrier function and supports the hypothesis that a loss of membrane CD146 by the described shedding process could be responsible for the observed increased paracellular permeability.

\section{Discussion}

CD146 is not only expressed on the surface of endothelial cells, where it is involved in the control of cell adhesion, but is also found as a soluble form in conditioned medium of cultured human endothelial cells and in human plasma (Bardin et al., 1998; Bardin et al., 2003). To elucidate the role of the soluble form of this adhesion molecule, we analyzed various stimuli for their ability to induce the formation of sCD146 in cultured endothelial cells. The calcium ionophores A23187 and ionomycin both induced the formation of sCD146 indicating that an increase in intracellular calcium concentrations mediates the signal for sCD146 generation. Interestingly, the engagement of CD146 by its specific monoclonal antibody in human umbilical vein endothelial cells initiates an outside in signaling cascade that results in calcium influx (Anfosso et al., 2001). This observation suggests that calcium influx could be the physiological response of endothelial cells to the engagement of CD146 by its ligand. Unfortunately, the ligand of CD146 is not yet identified. Probably, the generation of sCD146 is also initiated when the unknown ligand binds to CD146. This could be a regulatory feedback loop for the rapid downregulation of surface CD146 after the stimulation of this receptor as it is reported for other surface receptors such as CD14 (Bazil and Strominger, 1991).

Many membrane proteins also occur as a circulating, soluble form. These soluble forms are often derived from the membrane form by proteolytic cleavage of the extracellular domain. We propose that sCD146 is also generated by this mechanism. This is based on the observations that the increase in SCD146 in the cell culture super natant of stimulated cells was accompanied by a strong decrease of surface CD146 and that an inhibition of the Golgi secretory pathway did not reduce the formation of SCD146.

The enzymes involved in this ectodomain shedding include serino proteases, cysteino proteases and different types of metalloproteases (reviewed in Hooper et al., 1997; Dello Sbarba and Rovida, 2002). The group of metalloproteases can be further divided into matrix metalloproteases, membrane type MMPs (MT MMPs) and ADAMs. We tested various protease inhibitors and found that shedding of CD146 could only be blocked by MMP inhibitors. This indicates that MMPs are involved in CD146 shedding. MMPs are a family of zinc metallo endopeptidases. These enzymes are able to degrade extra cellular matrix proteins and are considered to play important roles in embryo development, morphogenesis and tissue remodeling, and in diseases such as arthritis, atherosclerosis and cancer cell invasion and metastasis (reviewed in Nagase, 1997). To date, 23 different human 

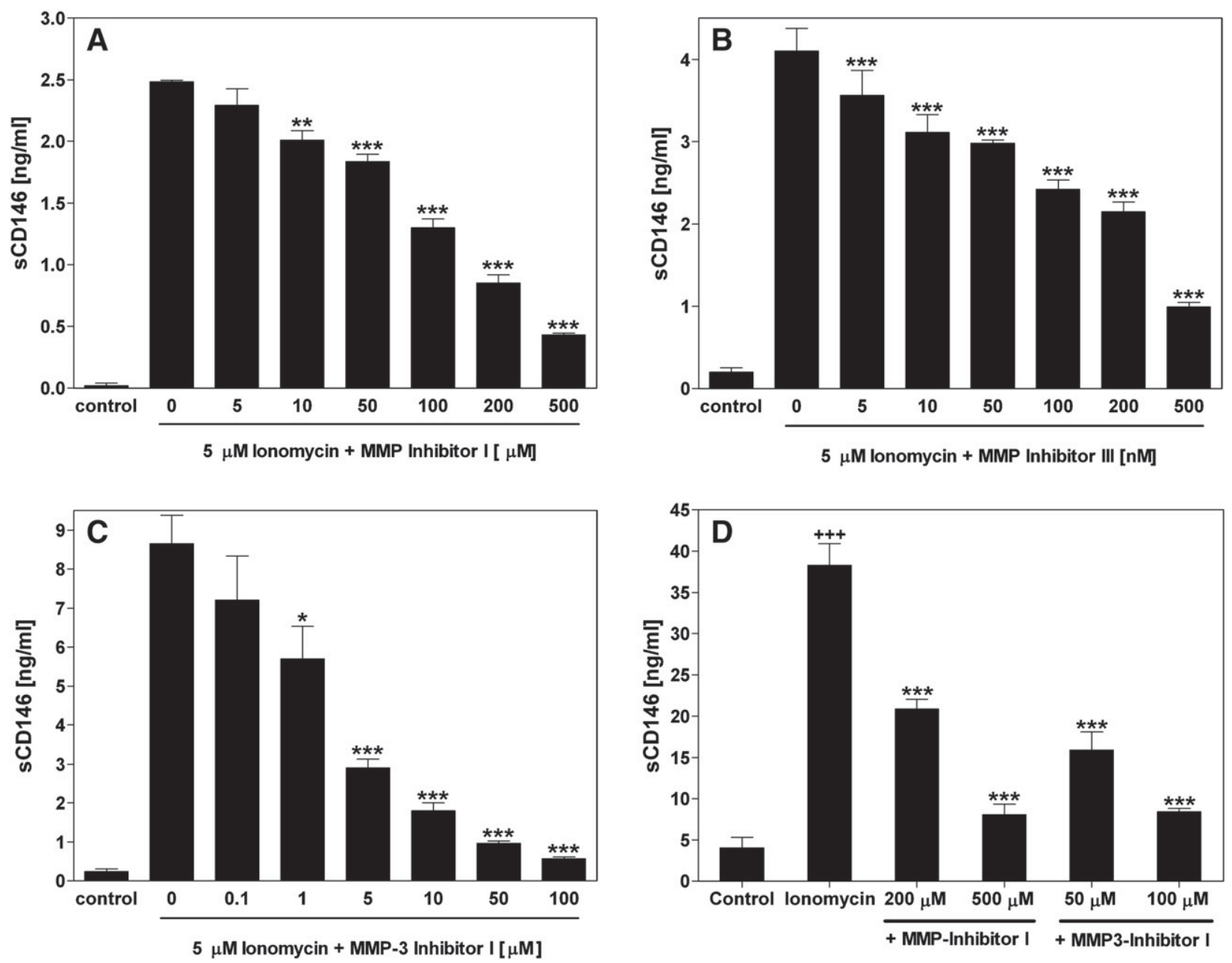

Fig. 4. MMP inhibitors prevent the ionomycin-induced shedding of CD146. (A-C) Cultured HMVEC-L were stimulated with $5 \mu \mathrm{M}$ ionomycin in combination with different concentrations of MMP inhibitors. After incubation for $2 \mathrm{~h}$, soluble CD146 was measured in the cell culture supernatants by ELISA. (A) MMP Inhibitor I, (B) MMP Inhibitor III, (C) MMP-3 Inhibitor I. ${ }^{*} p<0.05, * * p<0.01$ and ${ }^{* * *} p<0.001$ versus ionomycin. (D) HUVEC were stimulated with $10 \mu \mathrm{M}$ ionomycin in combination with different concentrations of MMP inhibitors. After incubation for $30 \mathrm{~min}$, soluble CD146 was measured in the cell culture supernatants by ELISA. ${ }^{+++} p<0.001$ versus control, $* * * p<0.001$ versus ionomycin.

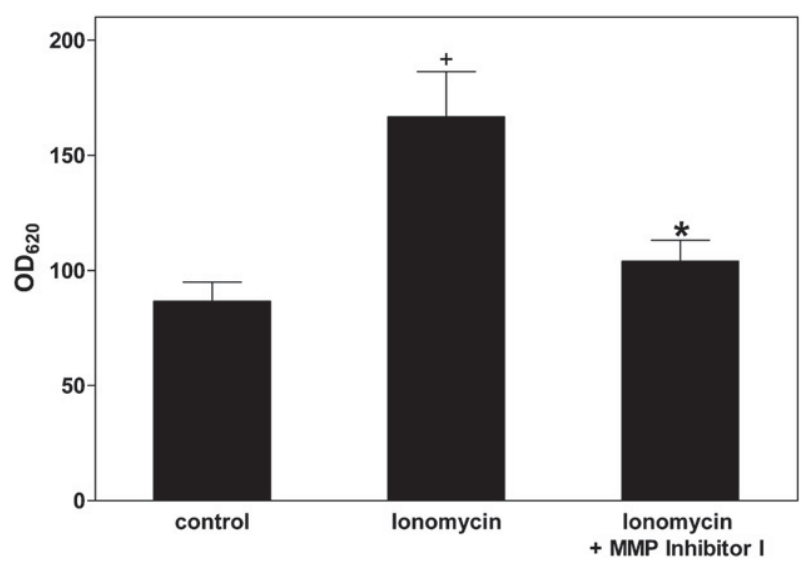

Fig. 5. MMP Inhibitor 1 blocks calcium-induced increase in vascular permeability. HMVEC-L were cultured on collagen-coated cell culture inserts for 5 days. The barrier function of the endothelial monolayer was assessed with Evan's Blue bound to bovine serum albumin which was added to the top well. The $5 \mu \mathrm{M}$ ionomycin $\pm 500 \mu \mathrm{M}$ MMP Inhibitor 1 was added to the top and the bottom wells and cells were incubated for $24 \mathrm{~h}$ at $37^{\circ} \mathrm{C}$. After the incubation time, absorbance of the medium in the bottom well was measured at $620 \mathrm{~nm} .{ }^{+} p<0.05$ versus control, ${ }^{*} p<0.05$ versus ionomycin.
MMPs have been identified (Somerville et al., 2003). Endothelial cells are reported to express MMP 1, MMP 2, MMP 3 and MMP 9 (Oda et al., 1999; Hummel et al., 2001), and the expression of MMP 3 can be induced by the angiogenic growth factor FGF B (Pintucci et al., 2003).

MMP 3 (stromelysin 1) or an MMP 3 like enzyme could be involved in CD146 shedding since an MMP 3 inhibitor was able to block ionomycin induced CD146 shedding. We further compared the calculated $\mathrm{IC}_{50}$ values of the three inhibitors for the CD146 sheddase with known $\mathrm{IC}_{50}$ values for MMP 3. In our inhibition experiments, we determined the $\mathrm{IC}_{50}$ values as $105 \mu \mathrm{M}$ for MMP Inhibitor I, $134 \mathrm{nM}$ for MMP Inhibitor III and $1.7 \mu \mathrm{M}$ for MMP 3 Inhibitor I. The IC $_{50}$ of these MMP inhibitors for MMP 3 are given from the manufacturer as $150 \mu \mathrm{M}$ for MMP Inhibitor I, $135 \mathrm{nM}$ for MMP Inhibitor III and $5 \mu \mathrm{M}$ for MMP 3 Inhibitor I. The comparison of these data with our calculated $\mathrm{IC}_{50}$ values suggests MMP 3 to be the CD146 sheddase.

Endothelial cells form a semipermeable barrier between blood and interstitium. Inflammatory mediators such as thrombin and histamine induce vascular leakage defined as increased permeability to plasma proteins and other solutes. Many of these inflammatory mediators trigger increased vascular permeability by increasing intracellular calcium concentrations which then mediate cytoskeletal reorganization and disassembly of VE cadherin at the adherens junctions (Sandoval et al., 2001; Tiruppathi et al., 2002; Vanden broucke et al., 2008; Schulz et al., 2008). In accordance with this, we observed increased permeability for albumin when confluent 


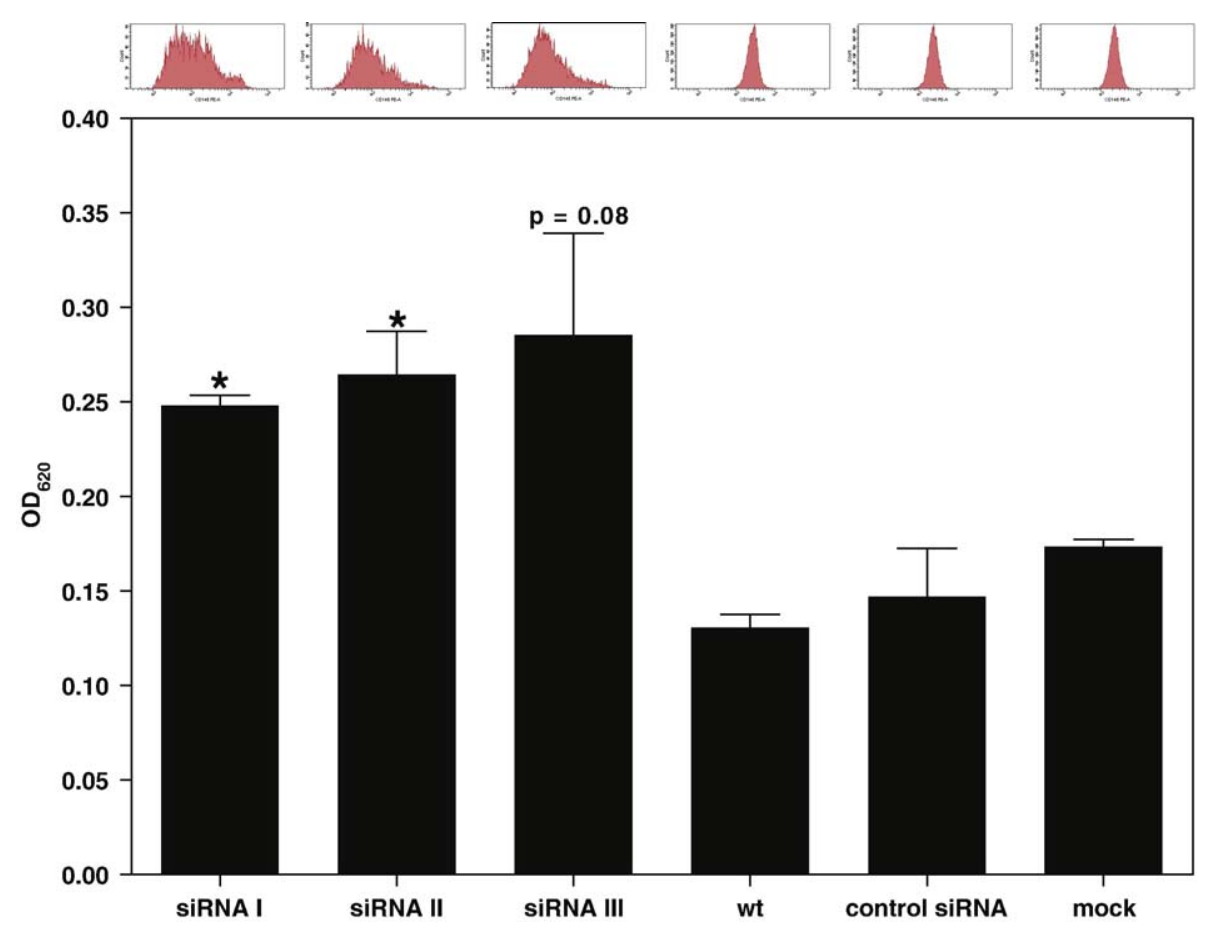

Fig. 6. Knockdown of CD146 increases vascular permeability. HUVEC were transfected with three different CD146 siRNAs or control siRNA or mock transfected. Knockdown of CD146 was controlled with flow cytometric analysis of CD146 expression. Transfected HUVEC were plated on collagen-coated cell culture inserts and the barrier function of the endothelial monolayer was assessed with Evan's Blue bound to bovine serum albumin which was added to the top well and cells were incubated for $24 \mathrm{~h}$ at $37^{\circ} \mathrm{C}$. After the incubation time, absorbance of the medium in the bottom well was measured at $620 \mathrm{~nm} .{ }^{*} p<0.05$ versus control siRNA.

monolayers of HMVEC L were stimulated with ionomycin. This calcium induced increase in permeability was prevented when CD146 shedding was blocked with an MMP inhibitor. CD146 is an endothelial cell adhesion molecule and is involved in the regulation of cell cohesion and paracellular permeability (Bardin et al., 2001; Solovey et al., 2001; Shih et al., 1997b). It is localized at the endothelial junction, but outside the adherens junction and colocalizes with the actin cytoskeleton (Bardin et al., 2001). The calcium induced loss of surface CD146 could therefore destabilize the cell cell contacts and result in the formation of intercellular gaps and increased paracellular permeability.

Since many inflammatory mediators stimulate calcium influx in endothelial cells (Vandenbroucke et al., 2008), shedding of CD146 could occur in many pathological conditions. Increased levels of sCD146 thus could reflect activated endothelial cells and impaired cellular contacts. Actually, increased sCD146 plasma levels were found in patients with chronic renal failure, a clinical setting which is characterized by increased vascular permeability (Bardin et al., 2003). Further sCD146 plasma levels were increased in patients with recurrent pregnancy loss (Pasquier et al., 2005), polymyositis (Figarella Branger et al., 2006) and diabetic nephropathy (Saito et al., 2007). This shows that shedding of CD146 also occurs in the human organism and not only in cell culture systems and indicates a pathophysiological relevance of CD146 shedding.

In conclusion, we could show that sCD146 is generated by the ectodomain shedding of membrane CD146 in a calcium induced, MMP dependent process. Our data indicate that surface CD146 plays a central role in cellular cohesion and could be an important regulator of vascular permeability. Therefore, CD146 and the CD146 sheddase are interesting targets to improve impaired endothelial barrier function.

\section{Acknowledgments}

This work was supported by grants of the Stiftung für Forschung in Tumordiagnostik und Prävention (STIFTUP); St. Gallen, Switzerland; the Eugen and Elisabeth Schellenberg Stiftung, Switzerland; the Thurgauische Stiftung für Wissenschaft und Forschung; and the Swiss State Secretariat for Education and Research.

\section{References}

Anfosso, F., Bardin, N., Vivier, E., Sabatier, F., Sampol, J., Dignat-George, F., 2001. Outsidein signaling pathway linked to CD146 engagement in human endothelial cells. J. Biol. Chem. 276, 1564-1569.

Bardin, N., Frances, V., Lesaule, G., Horschowski, N., George, F., Sampol, J., 1996. Identification of the S-Endo 1 endothelial-associated antigen. Biochem. Biophys. Res. Commun. 218, 210-216.

Bardin, N., Anfosso, F., Massé, J.M., Cramer, E., Sabatier, F., Le Bivic, A., Sampol, J., DignatGeorge, F., 2001. Identification of CD146 as a component of the endothelial junction involved in the control of cell-cell cohesion. Blood 98, 3677-3684.

Bardin, N., Frances, V., Combes, V., Sampol, J., Dignat-George, F, 1998. CD146: biosynthesis and production of a soluble form in human cultured endothelial cells. FEBS Lett. 421, 12-14.

Bardin, N., Moal, V., Anfosso, F., Daniel, L., Brunet, P., Sampol, J., Dignat-George, F., 2003. Soluble CD146, a novel endothelial marker, is increased in physiopathological settings linked to endothelial junctional alteration. Thromb. Haemost. 90, 915-920.

Bazil, V., Strominger, J.L., 1991. Shedding as a mechanism of down-modulation of CD14 on stimulated human monocytes. J. Immunol. 147, 1567-1574.

Dejana, E., 2004. Endothelial cell-cell junctions: happy together. Nat. Rev., Mol. Cell. Biol. 5, 261-270

Dello Sbarba, P., Rovida, E., 2002. Transmodulation of cell surface regulatory molecules via ectodomain shedding. Biol. Chem. 383, 69-83.

Figarella-Branger, D., Schleinitz, N., Boutière-Albanèse, B., Camoin, L., Bardin, N., Guis, S. Pouget, J., Cognet, C., Pellissier, J.F., Dignat-George, F., 2006. Platelet-endothelial cell adhesion molecule-1 and CD146: soluble levels and in situ expression of cellular adhesion molecules implicated in the cohesion of endothelial cells in idiopathic inflammatory myopathies. J. Rheumatol. 33, 1623-1630.

Hooper, N.M., Karran, E.H., Turner, A.J., 1997. Membrane protein secretases. Biochem. J. $321,265-279$.

Hummel, V., Kallmann, B.A., Wagner, S., Fuller, T., Bayas, A., Tonn, J.C., Benveniste, E.N. Toyka, K.V., Rieckmann, P., 2001. Production of MMPs in human cerebral endothelial cells and their role in shedding adhesion molecules. J. Neuropathol. Exp. Neurol. 60, 320-327.

Kang, Y., Wang, F., Feng, J., Yang, D., Yang, X., Yan, X., 2006. Knockdown of CD146 reduces the migration and proliferation of human endothelial cells. Cell Res. 16, 313-318.

Lehmann, J.M., Riethmuller, G., Johnson, J.P., 1989. MUC18, a marker of tumor progression in human melanoma, shows sequence similarity to the neural cell 
adhesion molecules of the immunoglobulin superfamily. Proc. Natl. Acad. Sci. U. S. A. 86, 9891-9895.

Nagase, H., 1997. Activation mechanisms of matrix metalloproteinases. Biol. Chem. 378, 151-160.

Oda, N. Abe, M. Sato, Y., 1999. ETS-1 converts endothelial cells to the angiogenic phenotype by inducing the expression of matrix metalloproteinases and integrin beta3. J. Cell Physiol. 178, 121-132.

Pasquier, E., Bardin, N., De Saint Martin, L., Le Martelot, M.T., Bohec, C., Roche, S., Mottier, D., Dignat-George, F., 2005. The first assessment of soluble CD146 in women with unexplained pregnancy loss. A new insight. Thromb. Haemost. 94, 1280-1284.

Pintucci, G., Yu, P.J., Sharony, R., Baumann, F.G., Saponara, F., Frasca, A., Galloway, A.C., Moscatelli, D., Mignatti, P., 2003. Induction of stromelysin-1 (MMP-3) by fibroblast growth factor-2 (FGF-2) in FGF-2-/- microvascular endothelial cells requires prolonged activation of extracellular signal-regulated kinases-1 and-2 (ERK-1/2). J. Cell Biochem. 90, 1015-1025.

Saito, T., Saito, O., Kawano, T., Tamemoto, H., Kusano, E., Kawakami, M., Ishikawa, S.E., 2007. Elevation of serum adiponectin and CD146 levels in diabetic nephropathy. Diabetes Res. Clin. Pract. 78, 85-92.

Sandoval, R., Malik, A.B., Minshall, R.D., Kouklis, P., Ellis, C.A., Tiruppathi, C., 2001 $\mathrm{Ca}(2+)$ signalling and PKCalpha activate increased endothelial permeability by disassembly of VE-cadherin junctions. J. Physiol. 533, 433-445.
Schulz, B., Pruessmeyer, J., Maretzky, T., Ludwig, A., Blobel, C.P., Saftig, P., Reiss, K., 2008 ADAM10 regulates endothelial permeability and T-Cell transmigration by proteolysis of vascular endothelial cadherin. Circ. Res. 102, 1192-1201.

Sers, C., Kirsch, K., Rothbacher, U., Riethmuller, G., Johnson, J.P., 1993. Genomic organization of the melanoma-associated glycoprotein MUC18: implications for the evolution of the immunoglobulin domains. Proc. Natl. Acad. Sci. U. S. A. 90, 8514-8518.

Shih, I.M., Speicher, D., Hsu, M.Y., Levine, E., Herlyn, M., 1997a. Melanoma cell-cell interactions are mediated through heterophilic Mel-CAM/ligand adhesion. Cancer Res. 57, 3835-3840.

Shih, L.M., Hsu, M.Y., Palazzo, J.P., Herlyn, M., 1997b. The cell-cell adhesion receptor Mel-CAM acts as a tumor suppressor in breast carcinoma. Am. J. Pathol.151, 745-751.

Solovey, A.N., Gui, L., Chang, L., Enenstein, J., Browne, P.V., Hebbel, R.P., 2001. Identification and functional assessment of endothelial P1H12. J. Lab. Clin. Med. 138, 322-331.

Somerville, R.P., Oblander, S.A., Apte, S.S., 2003. Matrix metalloproteinases: old dogs with new tricks. Genome Biol. 4, 216.

Tiruppathi, C., Minshall, R.D., Paria, B.C., Vogel, S.M., Malik, A.B., 2002. Role of Ca2+ signaling in the regulation of endothelial permeability. Vascul. Pharmacol. 39 173-185.

Vandenbroucke, E., Mehta, D., Minshall, R., Malik, A.B., 2008. Regulation of endothelial junctional permeability. Ann. N. Y. Acad. Sci. 1123, 134-145. 